\title{
UCRL-JRNL-206747
}

LAWRENCE LIVERMORE N A T IO N A L LABORATORY

\section{Raman Scattering of Azafullerene C48N12}

M. R. Manaa

September 23, 2004

Chemical Physics Letters 
This document was prepared as an account of work sponsored by an agency of the United States Government. Neither the United States Government nor the University of California nor any of their employees, makes any warranty, express or implied, or assumes any legal liability or responsibility for the accuracy, completeness, or usefulness of any information, apparatus, product, or process disclosed, or represents that its use would not infringe privately owned rights. Reference herein to any specific commercial product, process, or service by trade name, trademark, manufacturer, or otherwise, does not necessarily constitute or imply its endorsement, recommendation, or favoring by the United States Government or the University of California. The views and opinions of authors expressed herein do not necessarily state or reflect those of the United States Government or the University of California, and shall not be used for advertising or product endorsement purposes. 


\title{
Raman Scattering of Azafullerene $\mathrm{C}_{48} \mathrm{~N}_{12}$
}

\author{
M. Riad Manaa \\ Lawrence Livermore National Laboratory \\ Energetic Materials Center \\ P.O. Box 808, L-282 \\ Livermore, California, 94551
}

To be submitted to Chemical Physics Letters

\footnotetext{
*Email: manaa1@1lnl.gov
} 


\begin{abstract}
:
Raman scattering activities and Raman-active frequencies are reported for the minimum energy structure of azafullerene $\mathrm{C}_{48} \mathrm{~N}_{12}$ at the B3LYP/6-31G* level of theory. Analysis of the vibrational spectrum shows that the most intense IR and Raman bands are those associated with $\mathrm{C}-\mathrm{C}$ vibrations, and that strong IR and Raman $\mathrm{C}-\mathrm{N}$ vibrations occur below $1400 \mathrm{~cm}^{-1}$. Together with the recently reported infrared, optical absorption and $\mathrm{x}-$ ray spectroscopies, a complete identification of this cluster should now be feasible.
\end{abstract}


New exciting developments in fullerene doping have attracted much interest due to expectation for novel electronic, optical, and magnetic properties. [1] $\mathrm{C}_{48} \mathrm{~N}_{12}$ is one of several recently synthesized molecular systems in which the carbon atoms in the $\mathrm{C}_{60}$ cage are replaced either by nitrogen or boron counterparts. [2-5] Compared to $\mathrm{C}_{60}, \mathrm{C}_{48} \mathrm{~N}_{12}$ shows an enhancement of its second hyperpolarizibility by about $55 \%$, making it a good candidate for optical limiting applications. [6] $\mathrm{C}_{48} \mathrm{~N}_{12}$ could be used to build diamagnetic materials due to its enhanced diamagnetic shielding factor in the carbon atom. [7] Also, electron acceptor $\mathrm{C}_{48} \mathrm{~B}_{12}$ and donor $\mathrm{C}_{48} \mathrm{~N}_{12}$ have been shown to be promising components for molecular rectifiers, carbon nanotube-based $n-p-n(p-n-p)$ transistors and $p-n$ junctions. [8, 9] Moreover, cross-linked nano-onions with $\mathrm{C}_{48} \mathrm{~N}_{12}$ at the core [5] showed that the material is highly elastic yet exhibits an appreciable resilience, properties that render the nanostructured material ideal for wear-protective applications.

Several computational studies concerning the structure and spectroscopy of this intriguing cluster has since been reported. It was shown [10] that the global molecular structure of $\mathrm{C}_{48} \mathrm{~N}_{12}$ consists of extended aromatic rings of carbon (a total of eight), and in which the nitrogen atoms were distributed as one atom in each of the twelve pentagons (figure 1). This conformation in the buckyball, having $\mathrm{S}_{6}$ symmetry, allows each nitrogen atom to be separated from its neighboring nitrogen atom by at least one carbon atom, thus minimizing N-N repulsion. The overall stability of the cluster is enhanced over other isomers $[11,12]$ from added resonance energy contributions, while precluding a weaker nitrogen-nitrogen link. Consequently, several studies have determined the vibrational [12], magnetic [13], electronic and optical properties [14-16] of the ground state structure. Further computational studies on the condensed fcc electronic structure 
[17], nuclear spin statistics [18], and group theoretical analysis of vibrational modes and rovibronic levels [19] of this molecule have also appeared more recently.

To complete the full spectroscopic characterization of the $\mathrm{C}_{48} \mathrm{~N}_{12}$ cluster, in this brief letter I report the Raman spectrum as calculated using the B3LYP/6-31G* method. $[20,21]$ It was shown [22] that this level of theory provides accurate Raman activities and frequencies when compared with experimental results of $\mathrm{C}_{60}$. Together with the previously noted studies, e.g., infrared (IR) $[12,17]$ and electronic spectroscopy [14-16], an unambiguous experimental identification of $\mathrm{C}_{48} \mathrm{~N}_{12}$ should now be possible.

Structurally, the $\mathrm{S}_{6}$ optimized structure of $\mathrm{C}_{48} \mathrm{~N}_{12}$ shows the existence of one purely C-C double bond ( $s p^{2}$ hybridization, as in graphite) and one C-C single bond ( $s p^{3}$ hybridization, as in diamond), $1.363 \AA$ and $1.443 \AA$, respectively. This should be contrasted with the two bonds of the icosahedral $\mathrm{C}_{60}, 1.40$ and $1.45 \AA$.. [23] The delocalization of electronic clouds in the hexagonal ring of $\mathrm{C}_{48} \mathrm{~N}_{12}$ is demonstrated by similar C-C bond length in the $1.403-1.424 \AA$ A range at the B3LYP level. Two different types of nitrogen atoms are present, differing by the C-N bond length 1.443 and $1.424 \AA$.

Within the $\mathrm{S}_{6}$ group, the vibrational modes of transforms as $\Gamma_{v}=29\left(\mathrm{~A}_{\mathrm{g}}+\mathrm{A}_{\mathrm{u}}+\mathrm{E}_{\mathrm{g}}\right.$ $+E_{u}$ ). [19] The $u$ modes are IR active while the g modes are Raman active. Table I lists the calculated Raman active frequencies of the optimized minimum energy structure of $\mathrm{C}_{48} \mathrm{~N}_{12}$. Of the total 174 independent normal vibrations of this cluster, there are 58 vibrational modes that are Raman active. These modes are in turn classified into 29 doubly degenerate ( $\mathrm{E}_{\mathrm{g}}$ character) and 29 non-degenerate modes ( $\mathrm{A}_{\mathrm{g}}$ character). A similar classification of the IR active modes of $A_{u}$ and $E_{u}$ character has also been established. $[17,19]$ 
Figure 2 displays the calculated Raman scattering activities at the corresponding frequencies. The spectrum separates into two regions: the low frequency region (200-900 $\mathrm{cm}^{-1}$ ), and the high-frequency region (1100-1700 $\left.\mathrm{cm}^{-1}\right)$. Xie and co-workers have also determined a similar Raman spectrum feature of a low-lying isomer of $\mathrm{C}_{48} \mathrm{~N}_{12}$ (also of $\mathrm{S}_{6}$ symmetry) at the same level of theory. [22] It is noted that the most intense modes in figure 2 are the non-degenerate $A_{g}$ modes appearing at frequencies 494, 1170, 1242, 1389, 1531, 1613, and $1688 \mathrm{~cm}^{-1}$, with corresponding Raman activities of 75, 113, 85, 201, 186, 157, and $107 \AA^{4} / a . m . u$, respectively. All of the doubly degenerate modes exhibit low activities, around $20 \AA^{4} /$ a.m.u, with the exception of one mode appearing at frequency $1606 \mathrm{~cm}^{-1}$ and showing a strong activity of $79 \AA^{4} / \mathrm{a} . \mathrm{m} . \mathrm{u}$. Therefore, the most intense bands in both the low frequency region and the high frequency region are the non-degenerate $A_{g}$ modes. These two modes, located at 494 and $1389 \mathrm{~cm}^{-1}$, are almost the same as those of the strongest $\mathrm{A}_{\mathrm{g}}$ modes of $\mathrm{C}_{60}$, which have been appear at 490 and $1500 \mathrm{~cm}^{-1}$ as calculated at the B3LYP/3-21G level of theory. [22]

Figure 3 shows the vibrations associated with the most intense $A_{g}$ and $E_{g}$ modes of $\mathrm{C}_{48} \mathrm{~N}_{12}$. Both modes are dominantly associated with carbon-carbon vibrations at the fusion of hexagons and pentagons of fullerene cage. Earlier, the most intense IR active mode appearing at $1669 \mathrm{~cm}^{-1}$ was identified to correspond mainly with a C-C asymmetric stretch for the carbon atoms along the equator, one of which is separating a pair of nitrogen atoms. [17] Detailed examination of Raman-active vibrational modes reveals that most intense $\mathrm{C}-\mathrm{N}$ vibration is the low-frequency, $\mathrm{E}_{\mathrm{g}}$ mode at $494 \mathrm{~cm}^{-1}$. In contrast, we have found that the second strongest IR band, associated with the frequency $1309 \mathrm{~cm}^{-}$ 1, was identified to correspond to a C-N symmetric stretch. [17] From the IR and Raman 
spectra of this culster, we conclude that (i) the most intense IR and Raman bands are those associated with C-C vibrations, and (ii) strong IR and Raman $\mathrm{C}-\mathrm{N}$ vibrations occur below $1400 \mathrm{~cm}^{-1}$.

\section{Acknowledgments:}

This work was performed under the auspices of the U.S. Department of Energy by the University of California, Lawrence Livermore National Laboratory under contract number W-7405-Eng-48. 


\section{Figures Caption:}

Figure 1. The $\mathrm{S}_{6}$ symmetry molecular structure of $\mathrm{C}_{48} \mathrm{~N}_{12}$. $\mathrm{N}$ indicates the positions of nitrogen atoms.

Figure 2. Raman scattering activities (in $\AA^{4} /$ a.m.u) of $\mathrm{C}_{48} \mathrm{~N}_{12}$. Solid circles are the actual data, while the line is a fit to guide the eye.

Figure 3. The most intense Raman - active modes with frequencies $1389 \mathrm{~cm}^{-1}\left(\mathrm{~A}_{\mathrm{g}}\right)$ and $1606 \mathrm{~cm}^{-1}\left(\mathrm{E}_{\mathrm{g}}\right)$. Vectors represent the normal modes. 
Table I. Frequencies (in $\mathrm{cm}^{-1}$ ) of Raman active modes of $\mathrm{C}_{48} \mathrm{~N}_{12}$.

\begin{tabular}{l|l}
\hline \multicolumn{1}{c|}{ Non-degenerate modes } & \multicolumn{1}{c}{ Doubly degenerate modes } \\
\hline $269,379,425,455,483,494,552,570$, & $251,162,362,397,443,505,557,583$, \\
$582,602,663,692,716,766,819,843$, & $622,653,687,720,762,777,836,847$, \\
$1081,1097,1170,1242,1262,1327$, & $1061,1134,1162,1202,1286,1337$, \\
$1389,1401,1448,1468,1531,1613$, & $1361,1394,1414,1454,1590,1606$, \\
1688 & 1665 \\
\hline \hline
\end{tabular}




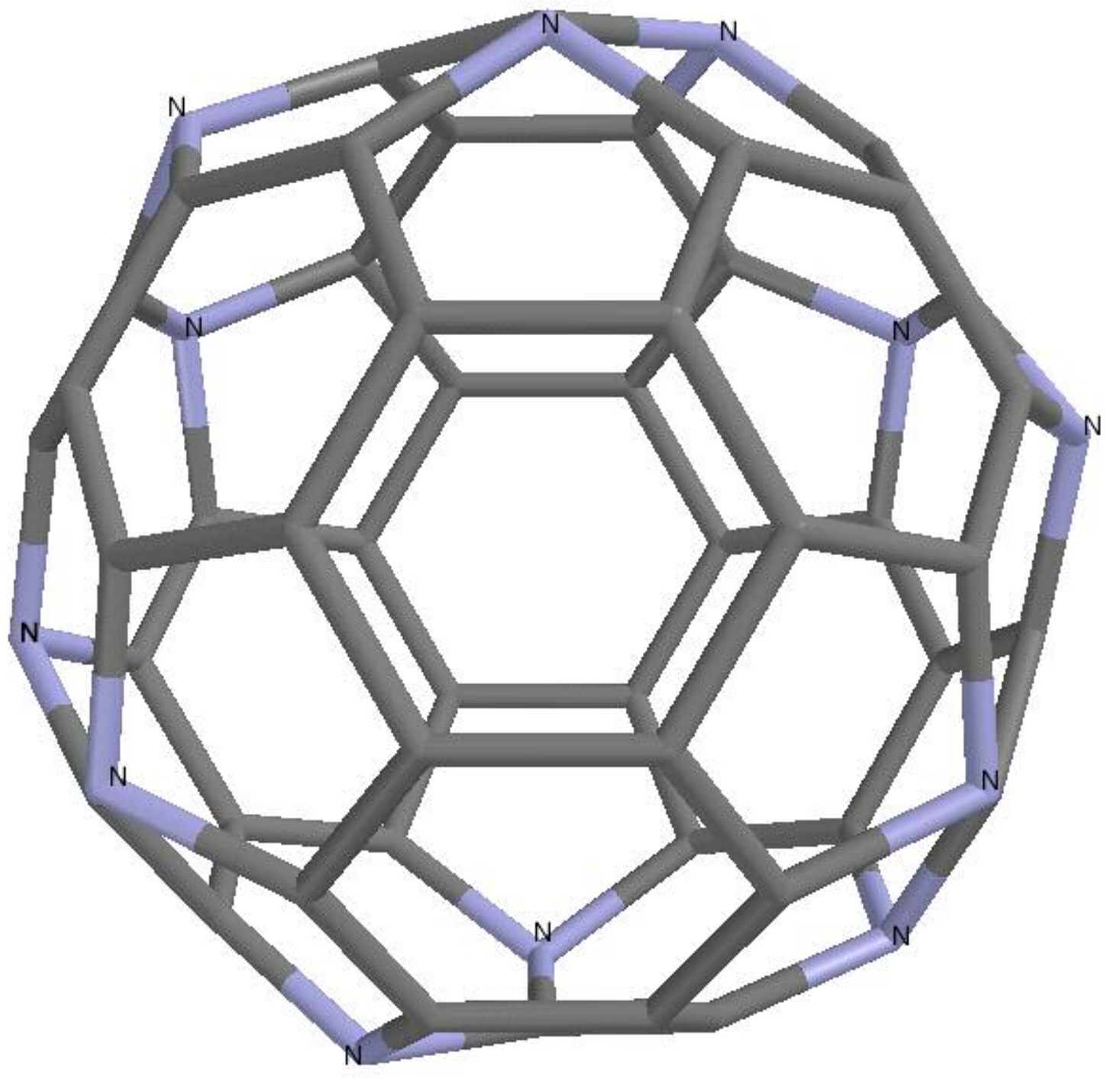

Manaa : Figure 1. 


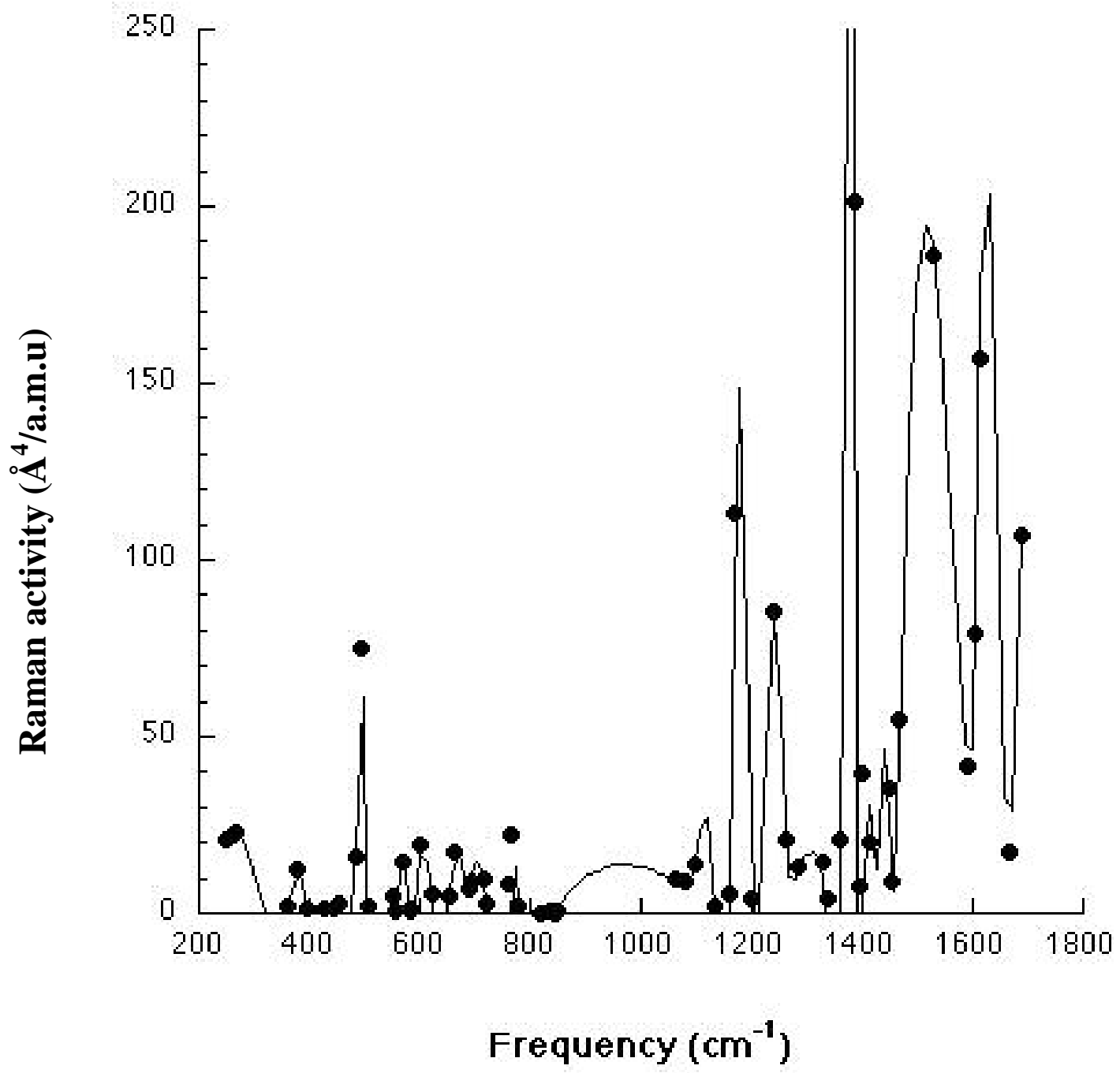

Manaa : Figure 2 


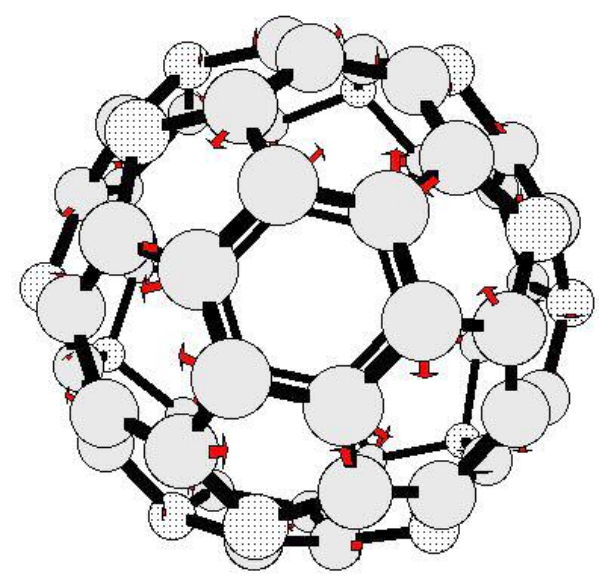

$$
\text { Ag: } 1389 \mathrm{~cm}^{-1}, 201 \AA^{4} / \text { a.m.u }
$$

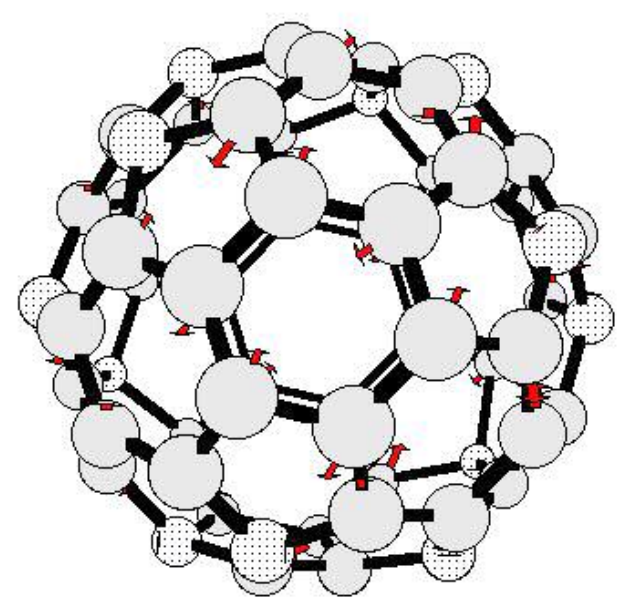

$$
\text { Eg: } 1606 \mathrm{~cm}^{-1}, 79 \AA^{4} / \mathrm{a} . \mathrm{m} . u
$$

Manaa : Figure 3 


\section{REFERENCES}

[1] W. Andreoni (Ed.), The Physics of Fullerene-Based and Fullerene-Related Mateials, Kluwer, New York, 2000.

[2] J. C. Hummelen, B. Knight, J. Pavlovich, R. Gonzalez, and F. Wudl, Science 269 (1995) 1554.

[3] T. Guo, C. M. Jin, and R. E. Smalley, J. Phys. Chem. 95 (1991) 4948.

[4] S. Glenis, S. Cooke, X. Chen, and M. N. Labes, Chem. Mater. 6 (1994) 1850.

[5] L. Hultman, S. Stafström, Z. Czigany, J. Neidhardt, N. Hellgren, I. F. Brunell, K. Suenaga, and C. Colliex, Phys. Rev. Lett. 87, (2001) 225503.

[6] R. H. Xie, G. W. Bryant, L. Jensen, J. Zhao, and V. H. Smith Jr., J. Chem. Phys. 118, (2003) 8621.

[7] R. H. Xie, G. W. Bryant, and V. H. Smith Jr., Chem. Phys. Lett. 368, (2003) 486.

[8] R. H. Xie, G. W. Bryant, J. Zhao, V. H. Smith Jr., A. Di. Carlo, and A. Pecchia, Phys. Rev. Lett. 90, (2003) 206602.

[9] M. R. Manaa, Chem. Phys. Lett. 382, (2003) 194.

[10] M. R. Manaa, D. W. Sprehn, and H. A. Ichord, J. Am. Chem. Soc. 124, (2002) 13990.

[11] S. Stafström, L. Hultman, and N. Hellgren, Chem. Phys. Lett. 340, (2001) 227.

[12] M. R. Manaa, D. W. Sprehn, and H. A. Ichord, Chem. Phys. Lett. 374, (2003) 405.

[13] R. G. Viglione and R. Zanasi, Phys. Chem. Chem. Phys. 6, (2004) 295.

[14] B. Brena and Y. Luo, J. Chem. Phys. 119, (2003) 7139.

[15] R. H. Xie, G. W. Bryant, G. Sun, M. C. Nicklaus, D. Heringer, T. Frauenheim, M. R. Manaa, V. H. Smith Jr., Y. Araki, and O. Ito, J. Chem. Phys. 120, (2004) 5133.

[16] X. Blase and P. Ordejon, Phys. Rev. B 69, (2004) 085111.

[17] M. R. Manaa, Solid State Commun. 129, (2004) 379.

[18] K. Balasubramanian, Chem. Phys. Lett. 391 (2004) 69.

[19] K. Balasubramanian, Chem. Phys. Lett. 391 (2004) 64.

[20] A. D. Becke, J. Chem. Phys. 98, (1993) 5648.

[21] C. Lee, W. Yang, and R. G. Parr, Phys. Rev. B 37, (1988) 785.

[22] R.H. Xie, G. W. Bryant, and V. H. Smith, Jr., Physical Rev. B 67, (2003) 155404. 
[23] C. S. Yannoni, P. P. Bernier, D. S. Bethune, G. Meijer, and J. R. Salem, J. Am. Chem. Soc. 113 (1991) 3190. 